\title{
ETNICIDADES CENTRADAS Y DESCENTRADAS. UNA PROPUESTA DESDE LA PERSPECTIVA RELACIONAL PARA LA COMPRENSIÓN DE PROCESOS ÉTNICOS CONTEMPORÁNEOS
}

\section{CENTERED AND OFF-CENTERED ETHNICITIES. A PROPOSAL FOR THE UNDERSTANDING OF CONTEMPORARY ETHNIC PROCESSES FROM A RELATIONAL PERSPECTIVE}

\author{
Luis Nicolás Olivos Santoyo* \\ DOI: https://doi.org/10.31644/ED.V7.N2.2020.A07
}

\begin{abstract}
Resumen: En el presente ensayo se pone a prueba una teoría de la etnicidad fundada en el enfoque relacional, donde se hace uso de las ideas de centralidad y descentralidad para caracterizar algunos fenómenos étnicos contemporáneos en el país. Para fundamentar las ideas me apoyo en una etnografía comparada realizada entre los rarámuris de Chihuahua y los mixtecos de Oaxaca, a quienes trato de comprender bajo ese modelo que expongo y explicar desde éste las situaciones actuales de persistencia ante un mundo global.
\end{abstract}

Palabras Claves: enfoque relacional, etnicidad, persistencia, mixtecos, rarámuris.

\footnotetext{
1 Profesor investigador de la Universidad Autónoma de la Ciudad de México, México. Antropólogo social por la Escuela Nacional de Antropología e Historia, México, maestro en Filosofía y doctor en Ciencias Antropológicas por la Universidad Autónoma Metropolitana, Unidad Iztapalapa, México. Ha realizado investigación de campo entre los rarámuri de Chihuahua y entre los mixtecos de Oaxaca. Correo-e: luis.nicolas.olivos@uacm.edu.mx. ORCID: 0000-0002-7283-8414

Fecha de recepción: 08/01/2020. Fecha de aceptación: 01/04/2020. Fecha de publicación: $31 / 07 / 2020$
}

(c) BY-NC-ND Páginas $194-221$ 
Abstract: In this essay a theory of ethnicity based on a relational approach is tested, where the ideas of centrality and decentrality are used to characterize some contemporary ethnic phenomena in Mexico. To support these ideas, I rely on comparative ethnography carried out among the Raramuri of Chihuahua and the Mixteco of Oaxaca, using the model I propose to explain the current situations of persistence in a global world.

Keywords: relational perspective, ethnicity, persistence, mixteco, raramuri.

\section{Introducción}

Este trabajo tiene una doble intención. Por un lado, busca contribuir a las reflexiones contemporáneas sobre los procesos de adscripción y persistencia de poblaciones que se diferencian étnicamente, para lo cual propongo un modelo teórico de análisis que hace de las relaciones centralizadas y descentralizadas las categorías que permiten pensar la vitalidad y vigencia de los reconocimientos étnicos, así como la crisis de identidad étnica. Por otro lado se trata de un trabajo que, si bien tiene intenciones teóricas más generalizadoras, busca contribuir al debate sobre las dinámicas culturales y sociales de las poblaciones indígenas en el México contemporáneo, en especial en pueblos que históricamente se consideran como expresiones actuales de dos proyectos civilizatorios: los rarámuri, un pueblo del noroeste mexicano, heredero de los yuto-aztecas oasisamericanos, y el otro caso refiere a uno de los pueblos oaxaqueños descendientes de una de las civilizaciones militaristas y teocráticas más importantes de lo que se llamó Mesoamérica: los mixtecos.

Para operar los conceptos de centralidad y descentralidad, los encuadro en un enfoque relacional sobre las etnicidades, el cual se aleja de las perspectivas esencialistas que han dominado la literatura sobre la temática de la etnicidad y los grupos étnicos en ciencias sociales. Mi intención es proponer un modelo comprensivo que dé cuenta de las dinámicas culturales y sociales asociadas con la manera de vivir y relacionarse con los recursos étnico-culturales que disponen los sujetos en sus entornos locales, haciendo énfasis en conocer 
cómo el tipo de relación y sus dinámicas o fortalecen los procesos de anclaje y reconocimiento étnico, o tienden a dificultar las persistencias étnicas.

Llegar a esta postura ha sido parte de las reflexiones que he realizado desde mi experiencia de trabajo de campo en dos agregados étnicos diferentes, como son mixtecos y rarámuris. En el primer caso, he sido testigo de los mecanismos de persistencia a través de adaptaciones y readecuaciones de los valores étnicos con los cuales se identifican los mixtecos de Oaxaca, quienes expresan la vía plural y descentralizada de construcción étnica y que actualmente muestran gran vitalidad a pesar de los embates de un mundo global que introduce nuevos valores, objetos y símbolos que son externos a los creados desde esta cultura étnica.

Por otro lado, los rarámuri, localizados en la Baja Tarahumara, son un grupo que en la actualidad aún se aferra a los elementos étnicos que han sido referente de su identidad, muchos de los cuales fueron definidos desde la época prehispánica y colonial, pero que cada vez más son trastocados por los embates del mundo mestizo, del mundo occidental y global. Los rarámuri representarían ese tipo de etnicidades centradas en torno a pocos y marcados referentes, cuya persistencia siempre está puesta en riesgo ante los retos del cambio cultural y social.

Ahora bien, estos dos casos sirven para ilustrar el destino de algunos de los pueblos indígenas ante este nuevo milenio. El siglo que dejamos atrás afortunadamente no cumplió las expectativas de los analistas más pesimistas (Clifford, 1999), que veían el fin de las etnicidades como el destino final de los grandes procesos globales. Pero, a su vez, es un siglo que tampoco ha sido muy alentador para la persistencia de algunas de las identidades étnicas, para la supervivencia de lenguas originarias, o bien para la reproducción de creencias y visiones del mundo generadas desde otros mundos posibles. Así, no todas las poblaciones indígenas tienden a desaparecer, pero tampoco dejamos de padecer fuerzas que atentan contra estas manifestaciones de la diversidad, por lo que comprender los mecanismos que hacen a unas permanecer y a 
otras entrar en zonas de riesgo es una tarea que se puede realizar desde el conocimiento empírico de casos ${ }^{1}$.

\section{Primer sentido de centralidad y descentralidad en la comprensión de proyectos civilizatorios}

Gran parte de los etnógrafos que hacíamos investigación en el noroeste mexicano partíamos de un supuesto en el que los procesos civilizatorios que diferenciaban a las sociedades mesoamericanas de aquellas comprendidas en la gran zona denominada Oasisamérica y Aridoamérica se explicaban por los grados de centralidad y no centralidad en términos sociales, económicos y políticos que definieron a los dos tipos de civilización. Veíamos que las culturas originarias que se asentaron en montañas y valles de la Sierra Madre Occidental se podrían caracterizar como un tipo de sociedad poco centralizada y, más bien, tendiente a la dispersión geográfica y a la carencia de dinámicas aglutinadoras o concéntricas en lo comunitario y en la organización social.

Esta tesis la obtuvimos de la lectura que hacíamos de Edward Spicer, en particular de su libro intitulado Ciclos de Conquista (1997), donde afirmaba que, al contacto con los españoles, el panorama civilizatorio de los pueblos nativos de lo que hoy es México comprendía tres formatos o modos de vida: en primer lugar, los cazadores recolectores nómadas, en segundo, las sociedades estatales y sedentarias, y finalmente las formas de vida de agricultores semisedentarios.

Las sociedades estatales se conformaban por pueblos asentados en territorios fijos y bien delimitados, los cuales eran administrados y controlados, al igual que los pobladores de dicho espacio, por un poder central y mediante estructuras institucionales que actuaban a nivel de lo político, lo económico y lo religioso. Esta descripción correspondía a las sociedades que el antropólogo alemán Paul Kirchhoff (1960) denominó culturas mesoamericanas (donde él incluía a los mixtecos y a los grupos otomangues del estado de Oaxaca). Culturas que compartían, entre otros elementos sociales y culturales, el que sus poblaciones asumían el formato de grandes y medianas ciudades religiosas, políticas o militares. Ciudades que además de ser espacios de concentración

\footnotetext{
${ }^{1}$ Deseo insistir que mi intención es poner a prueba un modelo analítico y comprensivo que, en lo particular, me permite la comparación de dos expresiones étnicas que han sido objeto de mi interés. No dudo que a otros lectores les sirva para la comparación de poblaciones contiguas histórica, cultural o geográficamente, o bien, para aquellas que son distantes. De igual forma asumo que muchas otras expresiones quedan fuera de este modelo y que se requiere generar otros que permitan comprender las persistencias o rupturas étnicas.
} 
de poder y de control administrativo-burocrático, resultaron ser los sitios en torno a los que giraban prácticas económicas de distribución y comercio, como fueron los mercados, que eran escenarios donde se ofertaban todo tipo de servicios económicos, pero también los religiosos, que sin lugar a duda fueron un elemento central para la configuración de estas ciudades y la generación de dinámicas centralizadoras.

Además de ser el artífice de la idea de Mesoamérica como región cultural, Paul Kirchhoff (2008) señaló también que al norte de la frontera mesoamericana encontramos otro mundo: el de los agricultores del norte, al que bautizó como Oasisamérica, el cual representa el tercer formato señalado por Spicer. Kirchhoff explicaba esta área como un eslabón entre las grandes civilizaciones mesoamericanas y las sociedades cazadoras y recolectoras del norte. Para él, estas sociedades oasisamericanas son el producto de un proceso de tensión entre una evidente expansión del modelo civilizatorio que proviene de Mesoamérica y que se dirige hacia tierras septentrionales. Pero también son el producto de una fase de pérdida de los rasgos mesoamericanos (ideas religiosas, formatos de organización social y política, concepciones e imaginarios del espacio y el mundo) que, según Kirchhoff, se vivía de manera aguda en el momento de la conquista. Pero resalta el antropólogo alemán que lo más acuciante fue el debilitamiento de los modelos agrícolas intensivos de producción, así como la adopción de los modelos cazadores y recolectores debido al intenso contacto de estas regiones con las bandas nómadas que subsistían con base en este último modelo.

Esta idea fue retomada tanto por Spicer (1997) como por muchos investigadores del noroeste, entre los que destacan Alejandro Figueroa (1985), Juan Luis Sariego (2002) y Eduardo Gotés (2012). Ellos sostenían que los agricultores del noroeste, es decir las sociedades de Oasisamérica, fueron uno más de los proyectos civilizatorios que los españoles encontraron en estas tierras. A diferencia de las grandes ciudades y pueblos mesoamericanos y de las bandas nómadas de cazadores-recolectores de las culturas de la llamada Aridoamérica, las sociedades oasisamericanas se distinguieron por tener formatos de organización social, política y económica intermedios, como fue la agricultura a pequeña escala combinada con la recolección y la caza. También se diferenciaron por haber generado formatos de asentamiento más nucleares y estacionarios, a diferencia de los que fueron propios de las bandas de cazadores 
y recolectores, pero menos centradas, localizadas en un territorio con fronteras fijas y con instituciones centrípetas, como los centros ceremoniales y políticoadministrativos que le dieron su fisionomía a los pueblos de Mesoamérica.

A este tipo de residencia en espacios fijos y dispersos Spicer lo bautizó como rancherías y las caracterizó como el formato de asentamiento y organización social prototipo de las sociedades oasisamericanas del noroeste. Se trataba de formas de organización político territorial cuyo eje eran las relaciones de parentesco y no las de clase, estamentos o ciudades, y que no se regían bajo la lógica de un Estado-territorio; así, para Kirchhoff, se trataba de "una versión provinciana o rústica de su contraparte mesoamericana" (Kirchhoff, 2008: 87). O bien, como lo destacaban los cronistas que llegaron a la región de Chínipas en el siglo XVII, a quienes les llamó la atención la forma de vida familiar que implican las rancherías, adquieren la forma de un pueblo o comunidad y en el marco de este espacio se resuelven todos los aspectos de la vida social y cultural, por lo que "...no les atrae a buscar unos de otros lo que causa el comercio y comunicación en los hombres” (González, 1984:100).

De tal manera, estas sociedades carecían de instituciones cuyo proceso de desarrollo condujera a las relaciones de tipo centradas, como son los procesos de organización de trabajo colectivo a partir de una coordinación central del mismo, ya sea a través de un Estado despótico o una burocracia administrativa. Se carecía de instituciones religiosas que nuclearan a la población en torno a un centro ceremonial o espacios rituales compartidos por un gran número de personas, y que desembocaran en peregrinaciones, quizá con el caso huichol como excepción, a santuarios.

No fue propio de este sistema social el desarrollo de instituciones centralizadoras como formas de gobierno y cargos religiosos y cívicos propios de las culturas del sur. No experimentaron la creación de prácticas aglutinadoras, como son los tequios y las faenas colectivas, o sistemas de redistribución y reciprocidad centrales, como son las mayordomías, las fiestas patronales y demás figuras culturales que distinguen a las sociedades herederas del mundo mesoamericano.

Lo anterior no quiere decir que, para algunos fines como la guerra, no se dieran procesos de articulación de lo disperso en torno a una idea de "nación", como la llamaron los cronistas y colonos del noroeste, o que existieran dinámicas festivas y rituales que vincularan a los miembros de una ranchería 
con otras. Sin embargo, como lo ha indicado Carl Lumholtz (1986), la idea de pueblo, su uso y apropiación es un derivado de la acción misionera jesuita, misma que trató de congregar a los rarámuri alrededor de una iglesia que serviría como centro religioso y político, y que poco a poco se instauraría en los imaginarios como el referente colectivo y de adscripción al centro, a su iglesia y a su santo. Así, la centralidad de esta política, que se agudizó con el advenimiento del Estado nación posrevolucionario y su política de integración indigenista, enfrentó pronto el dominio de la tendencia centrífuga de la dispersión y la descentralidad que caracterizó, para estos autores, a las sociedades del noroeste desde su origen.

Si bien el modelo de centralidad y descentralidad se volvió un modelo explicativo muy utilizado para dar cuenta de las diferencias entre procesos civilizatorios tan contrastantes como los existentes entre los grupos indígenas del noroeste y los del centro-sur del país ${ }^{2}$, la ecuación entre lo centrado y descentrado se puede invertir. Mi propuesta aquí es invertirlo como un recurso heurístico útil para comprender las formas en que los sujetos rarámuris y mixtecos se relacionan con los elementos étnicos originarios y nuevos en su vida cotidiana. Me sirve además como auxiliar para explicar las persistencias y viabilidad de estas y otras etnicidades en el mundo contemporáneo: tema que abordaré en las páginas siguientes, primero desde la etnografía y posteriormente desde la reflexión teórica.

\section{Otra vuelta de tuerca a los sentidos de centrado y descentrado en la comprensión de los procesos de reconocimiento étnico}

Rarámuris y $\tilde{n} u$ savis ${ }^{3}$ son habitantes de regiones montańosas que han aprovechado los valles y planicies para emplazar y diseminar ahí los diversos asentamientos donde viven hombres y mujeres que se identifican con ambos constructos étnicos. Sin embargo, el patrón de residencia y la forma de

\footnotetext{
${ }^{2}$ Este modelo fue recurrente en los etnógrafos de la Sierra Tarahumara, como Juan Luis Sariego, Eduardo Gotés, entre otros, para insistir en la demarcación tajante entre las formas de vida de las sociedades del norte de México en relación con las que se englobaban en la tradición mesoamericana.

${ }^{3}$ Utilizaré indistintamente, por motivos de estilo narrativo, las palabras rarámuri y tarahumara para referirnos al mismo conjunto étnico, y ñu savi o mixtecos para nombrar al otro grupo que se aborda en este trabajo.
} 
apropiación del espacio es notablemente diferente y se explica por los proyectos civilizatorios que en estos escenarios se desarrollaron.

A lo largo de las montañas de la Sierra Madre Occidental, en su porción chihuahuense, los territorios rarámuris se distinguen por ser esos enclaves de dos o más grupos familiares (unidades domésticas) que se reconocen como rancherías ${ }^{4}$. Son espacios donde transcurre la vida cotidiana de los habitantes, siendo el escenario donde se llevan a cabo la mayor parte de las interacciones que dotan de identidad a los miembros de este agregado étnico. Entre éstas, encontramos los lazos de cooperación y reciprocidad, el desarrollo de importantes eventos de la vida festivo-ritual como son las ceremonias de patio y la reproducción de las ideas del mundo a través de las charlas en los hogares. Pero, lo más importante es que se convierten en espacios donde se reproducen valores identitarios centrales, como son el uso de la lengua y la vestimenta tradicional, principalmente en mujeres, aunque en algunas regiones de la Sierra Tarahumara también los hombres siguen conservando la vestimenta.

Como ya mencionamos, la herencia colonial tuvo, entre otros impactos, una impronta en el formato de definición de los territorios y del paisaje étnico. La autonomía espacial y la reproducción de la idea de colectividad centrada en las rancherías tienen en la noción de pueblo un nuevo referente. Así, en torno a una iglesia, y posteriormente alrededor de las instancias de gobierno como escuelas y clínicas de salud, se construyó ese otro elemento que define al estilo de vida rarámuri: el pueblo.

El pueblo es una construcción identitaria que trasciende a las rancherías. Es decir, varias de éstas se reconocen pertenecientes a un pueblo en términos espaciales, pero, lo más importante es que los habitantes de estas realizan las fiestas mayores, como la Semana Santa o la fiesta del Santo, en la iglesia donde se aglutinan los diversos miembros de la comunidad. De igual manera, los niños acuden a las escuelas albergues localizadas en el "centro del pueblo". A pesar de que en el espacio que podríamos denominar el centro también encontramos asentamientos de población mestiza, el pueblo se podría pensar como una comunidad imaginada que revela a los miembros de las rancherías

\footnotetext{
${ }^{4} \mathrm{El}$ número de unidades domésticas y casas habitación que componen una ranchería es incierto y depende de la cantidad de terreno disponible para emplazar ahí una casa habitación, una parcela, espacios para almacenar las cosechas y otros enseres; junto a lo anterior, en el mismo lugar se construyen los corrales del ganado caprino, recurso fundamental para la subsistencia de las familias rarámuris.
} 
que existen unos otros con quienes comparten los mismos referentes que en las rancherías y unidades domésticas se configuran. Es decir, existen unos otros que piensan, hablan y visten como tarahumaras a pesar de que, en el espacio destinado para juntarse con ellos y realizar fiestas grandes, existe ese mundo no rarámuri que rechaza sus estilos de vida y que se impone como modelo de ser hegemónico al cual algunos rarámuris aspiran.

Por otra parte, los asentamientos mixtecos se caracterizan por ser núcleos poblacionales compuestos por un casco urbano y un conjunto de agencias que orbitan en torno a éste. El casco, o cabecera municipal, es el lugar donde se asienta el edificio del cabildo y el de las autoridades comunales, la iglesia central y en caso de existir barrios, las capillas barriales. También se emplazan allí las escuelas de diversos niveles y muchos otros servicios, como médicos, comerciales y de internet.

Es claro que, en términos del formato de asentamiento, la propiedad de centralidad le es más propia a los mixtecos que a los rarámuris. Si además observamos el tipo de instituciones y prácticas que enlazan a los miembros de la comunidad o pueblo, entre los ñu savi encontramos que en el gobierno local, ya sea en términos del cabildo o las autoridades de bienes comunales, las prácticas de organización para realizar trabajos en beneficio del pueblo (tequio), como limpiar, hacer obras urbanas, reforestar, cercar terrenos o trabajar para las fiestas otorgan una facticidad al pueblo. Es decir, a diferencia del nivel imaginario y difuso que tiene el sentido de pueblo entre los rarámuris; entre los mixtecos el pueblo se concretiza por una dimensión espacial que engloba los territorios y recursos que en éste se comprenden, además de un grupo de instituciones que motivan, y obligan a la interacción constante y permanente de los individuos que viven en un municipio, en sus barrios o en sus agencias.

$\mathrm{Si}$ bien entre los rarámuris se instauraron figuras como el gobierno indígena, las fiestas de la iglesia y el templo, más algunas prácticas de servicios colectivos como vigilar las escuelas y las clínicas, éstas son más bien prácticas e instituciones difusas y de actuación esporádica que se materializan solo en ciertas ocasiones. En cambio, las instituciones en la mixteca tienen un carácter permanente reconocido en la ley, en la Constitución del Estado de Oaxaca, como la forma de organizar el poder y autoridad en estos pueblos, elemento que les otorga una dimensión normativa que implica que la gente tiene que 
cumplir funciones en el gobierno y dar servicios al pueblo; incluso existen sanciones a todo aquel que no cumpla con las normas.

De tal manera que, mientras en los centros de los pueblos rarámuris nos encontramos algunas veces con los salones ejidales, los sitios (en Guadalupe Coronado le llamaban "el convento") donde se reúnen en ocasiones los gobernadores indígenas con la gente o sitios donde se guardan los artículos usados en fiestas, estos lugares sólo se ven concurridos en ocasiones festivas o por motivos de una reunión. En cambio, si miramos las presidencias municipales y las oficinas de los bienes comunales en los pueblos mixtecos, constatamos espacios reales de gobierno, donde siempre hay presencia de encargados o de algún otro miembro del cabildo o de los bienes comunales. Lo importante es que permanentemente hay personas que se adscriben al pueblo o municipio circulando por estos sitios para resolver algún asunto, realizar un trámite o porque se le convocó para realizar algún servicio.

Lo antes descrito sirve como elemento de apoyo para establecer que analizar la construcción de la etnicidad y la reproducción de las identidades étnicas en términos de lo centrado y lo descentrado puede ser invertido si el foco ya no es la herencia del proyecto civilizatorio en términos de la organización social, territorial y/o del tipo de instituciones que se han generado en uno u otro grupo indígena, como a continuación trataré de mostrar. Se invierte si miramos la manera en que los sujetos se reconocen y, por lo tanto, se adscriben a una etnicidad o, es decir, si analizamos cómo el devenir del formato civilizatorio y sus institucionalizaciones sostienen sujetos centrados o descentrados en torno a los valores étnicos que éstas instituciones se encargan de velar.

A pesar del aislamiento y dispersión de las rancherías rarámuris, éstas representan verdaderas comunidades de sentido que reproducen un mundo étnico muy compartido y homogéneo para los miembros que en éstas habitan. La gente rarámuri se produce ahí en torno a una serie de criterios objetivos de la etnicidad (Stavenhagen, 1992), de una imagen del mundo y de valores normativos que incluso actúan como esos valores supra ordinales (Berger y Luckmann, 1997).

He referido ya el tema de la lengua como un criterio de etnicidad importante para los tarahumaras y como un elemento que tiene en las rancherías un gran campo de posibilidades para su reproducción, esto porque el estigma y la discriminación que sobre ésta ha impuesto la sociedad mestiza se diluye. Sin 
buscar establecer un criterio único que permita definir lo que es la etnicidad rarámuri, sí puedo afirmar que la lengua es un aspecto central que marca la pertenencia, pero que, sobre todo, construye la distinción entre quién es rarámuri o indígena y quién no lo es. En mi trabajo de campo pude observar que incluso la gente que había migrado como jornalero a Sinaloa, Sonora o los valles de Chihuahua, siempre aseguraba haber conocido a otros tarahumaras, sólo que hablaban de una manera que ellos no entendían "por más que se acercaran". Aseguraban que eran tarahumaras aunque hablaban el mixteco u otro idioma y a pesar de que su lugar de origen fuera Chiapas o Oaxaca. Así, observamos que la lengua indígena y el hablarla es un criterio que permite y reproduce la identidad entre los rarámuris y resulta ser un fuerte criterio de adscripción étnica.

La vestimenta tradicional, principalmente de las mujeres, compuesta por sus faldas holgadas, camisas de colores y floreadas y el paño amarrado a la cabeza, se convierte también en un elemento identificador central. Son las mujeres, como en muchas culturas, los referentes primarios que cualquier sujeto tiene del grupo cultural al que se adscribe. Es decir, la diferencia frente a un Otro se elabora desde la propia figura primaria de socialización, como son las madres, hermanas y abuelas. Mujeres que, en los espacios de las rancherías y en las reuniones festivas en los pueblos, donde son mayoría, portan sus vestimentas como signo de identificación con otras mujeres con las que comparten algo más que las faldas y las blusas floreadas.

¿Y qué se comparte? Mencioné ya la lengua, pero también se comparte un estilo de vida, es decir, no sólo provenir y vivir en las rancherías y caminar horas para acudir a otra ranchería a celebrar alguna fiesta o deambular por montañas, barrancos y cañadas pastoreando chivas y borregos; también se participa en una forma de subsistir en la que todos colaboran, y que está anclada a una producción campesina en parcelas domésticas. Parcelas de cultivo de maíz en donde se elaboran dos bienes importantes que definen el ser rarámuri: las tortillas y la cerveza de maíz. La cerveza de maíz es una bebida fundamental para las fiestas, pero también se elabora para convidar a las personas que acuden a realizar algún trabajo en la parcela de alguna familia, 
o bien, para la celebración de algún tipo de ritual, como bendecir parcelas, animales, casas, o celebrar alguna curación.

Pero ese estilo de vida rarámuri también se sanciona y se reproduce a partir de lo extendida que está, entre los sujetos que se adscriben a esta cultura, una imagen del mundo y de las implicaciones normativas que ésta conlleva. Estas ideas del mundo aún se anclan a una narrativa muy compartida acerca de su propio origen como cultura, de su creación divina como el producto de un dios que los hace, que les otorga el mundo para su uso, que los pone a bailar y a sembrar, pero que al mismo tiempo les aconseja convivir en grupo, no pelear y, sobre todo, el ayudarse mutuamente. Las desventuras y crisis que viven tanto los individuos particulares como los pueblos enteros se explican por el hecho de que hubo un alejamiento de la norma fundamental, que es ayudar y estar siempre dispuestos a prestar ayuda sin la esperanza de una recompensa inmediata y otorgada por el que fue socorrido. Así, si a un sujeto no se le da la siembra, se le mueren sus animales o sufre algún percance, la respuesta inmediata de la gente es que se trata de una persona que no ayuda o no da korima.

El korima, como llaman los rarámuris a la acción de brindar ayuda y apoyo en múltiples aspectos de la vida diaria, resulta un claro representante de eso que Berger y Luckmann (1997) llamaron valores supraordinales, debido a que, en tanto idea del mundo como sistema normativo, atraviesan diversas esferas de la vida social de un grupo. Se apela al korima para referir a las ayudas domésticas que brindan sus miembros para lograr las tareas del hogar, pero también se utiliza el concepto cuando la gente es convocada para trabajar la parcela de un vecino o de un pariente. Korima es cualquier préstamo de algún bien, o el simple hecho de ir caminando, detenerse en una casa y que se le brinde agua, pinole o alguna tortilla. Incluso la gente rarámuri que ha migrado a las ciudades y pide dinero como limosna apela al término de korima, significando que lo brindado será una ayuda la cual será pagada al dador por un tercero y en otra ocasión, tal y como funciona el sistema en la sierra.

Si bien retomo y creo que el formato civilizatorio rarámuri se plasmó en una serie de instituciones y formas colectivas muy descentradas en relación con los mixtecos, en términos de los procesos de adscripción y configuración del sujeto étnico asumo que la formula se invierte. Como traté de mostrar en este breve bosquejo etnográfico sobre los tarahumaras de Chihuahua, los 
referentes étnicos son muy compartidos por los sujetos y éstos adquieren una fuerza centrípeta que permite la persistencia de la etnicidad en los actores. Incluso, como la experiencia etnográfica nos lo ha mostrado, la pérdida de la lengua y la renuncia a vivir en las rancherías como locus de la reproducción de la etnicidad, entre otras, ha generado que los sujetos abandonen el estilo de vida rarámuri y opten por diluirse en un mundo mestizo, el cual los rechaza por saber su origen, o por trasladarse a las ciudades y convertirse en un serrano de origen indígena y pobre.

En el otro caso que describo, si bien la población indígena que se adscribe como mixtecos es una de las mayoritarias a nivel nacional, con 517,665 miembros, según cálculos del INEGI ${ }^{5}$ (los rarámuris son cerca de 74,000), el idioma mixteco se considera una lengua en riesgo debido al acelerado proceso de abandono y desuso que en muchas localidades de la mixteca se está dando. Pero también se observa un hecho que quizá nos pondría a pensar sobre el papel que juega para la identificación como mixteco el uso de la lengua: mientras que el hablar la lengua muestra una tendencia a la baja, la identificación de individuos con una cultura mixteca es algo que va en aumento y que no sólo se restringe a los sitios de donde ellos son originarios, como Oaxaca, Guerrero o Puebla, sino que esta identificación se vive además en diversas ciudades del país y del extranjero.

Es palpable en la experiencia etnográfica que el percibirse y asumirse como mixteco no pasa por el hablar la lengua, por usar la vestimenta tradicional, por compartir una visión del mundo, ni por un estilo de vida anclado a un modo de resolver la subsistencia y al tipo de instituciones y prácticas que en torno a esta actividad se generan. Asumirse o percibirse como mixteco pasa por la posible combinación de uno o dos de estos elementos, o por la ponderación de uno y, en ocasiones, el rechazo de otros.

$\mathrm{Si}$ bien a nivel formal las estructuras normativas y las instituciones encargadas de vigilarlas y darles cauce tienen en la mixteca una concreción y centralidad mayor, lo cierto es que éstas, a diferencia de lo que observamos entre los rarámuris, no canalizan ni dirigen los procesos de construcción de la identidad étnica de los sujetos en particular. Mostrar la multiplicidad de formas en que los sujetos llevan a cabo los reconocimientos étnicos y transitan por uno u otro rasgo de la etnicidad rebasa las páginas disponibles y además

${ }^{5}$ http://cuentame.inegi.org.mx/hipertexto/todas_lenguas.htm 
se correría el riesgo de reducir estas formas tan rizomáticas y heterotópicas a unos casos.

Sin embargo, a manera de bosquejo etnográfico, podría afirmar que, si miramos la vida cotidiana de las personas que se definen mixtecos y los miramos en espacios como las agencias y el pueblo, encontramos que jóvenes $\mathrm{y}$ adultos, principalmente varones, se relacionan con otros sujetos y con el entorno a partir de ciertos intereses y preferencias afectivas. Así, una persona puede vincularse con otros debido a su gusto por el deporte o por su interés en los asuntos de la política local, para lo cual puede ser o no ser hablante de la lengua o compartir ciertas imágenes del mundo.

Es común que hombres y mujeres ñu savi, sobre todo jóvenes (y eso indica un proceso que se está agudizando), refieran que no conocen asuntos de la cosmovisión y creencias tradicionales, incluso algunos no las consideran verídicas. Sin embargo, por ejemplo, en San Pablo Tijaltepec, no se excluye que estos mismos jóvenes que no comparten ya una visión del mundo generalizada sean usuarios y personas muy competentes en el habla mixteco.

Este hecho contrasta con lo registrado en otros municipios vecinos a San Pablo, donde la lengua prácticamente se ha perdido o, en todo caso, solo se emplea por los adultos mayores. No obstante, los habitantes de estos lugares tienen una gran disposición para contar las historias que los abuelos narraban sobre las fuerzas y entidades que pueblan el mundo. Incluso son sitios donde la práctica de curaciones como el espanto y daños debido al nahual se mantienen vigentes.

Un ejemplo de este proceso de reconocimiento étnico, que posibilita las relaciones con diversos elementos culturales y sociales, así como el rechazo o abandono de otros a nivel de los individuos, es que un sujeto que se reconoce como miembro de una comunidad mixteca opte por estilos de vida diferentes a los de sus ancestros, sin negar con ello su identificación con la etnicidad. De tal manera, se observa en las nuevas generaciones que el abandono del estilo de

\footnotetext{
${ }^{6}$ En la región de la Mixteca Alta, cuando la gente refiere a su nahual, no hace la distinción, como lo hace la literatura antropológica, entre seres (que pueden ser animales o fenómenos naturales como el rayo o la lluvia) que marcan el destino de una mujer y un hombre al ser los causantes de una enfermedad o muerte. O bien nahual como aquel ser (animales básicamente, pero también fenómenos como tornados que se piensan son serpientes que vuelan) en el cual algunas personas tienen la capacidad de convertirse y realizar fechorías o afecciones como robos, raptos o encantamientos.
} 
vida campesino va de la mano con la aparición de otras formas de conducción de la vida asociadas a actividades como el comercio, los servicios o el empleo como profesionistas (maestros, médicos, contadores, arquitectos, ingenieros, entre otros). Sin embargo, estos actores pueden ser activos participantes en los asuntos políticos de la comunidad o asiduos participantes en mayordomías o comités de fiestas. Esta experiencia me ha permitido conocer profesionistas que hablan el mixteco, que tienen consideración a las creencias de sus abuelos y no las ponen en duda, pero que, sin embargo, apuestan por estilos de vida diferentes e incluso tienen un rechazo y crítica al formato campesino de vida, como lo hacía notar uno de nuestros interlocutores: "no entiendo por qué siguen sembrando si en ocasiones es más costoso pagar mozos, semillas, fertilizante y en temporadas se cosecha muy poco o nada. Eso detiene el progreso de los pueblos y su gente".

Son pocos los pueblos donde la vestimenta típica se usa en la vida ordinaria, ésta solo se ha convertido, en la mayoría de los municipios de la mixteca, en un referente que se hace patente cuando se promueve su uso para eventos escolares o cuando las madrinas (mujeres encargadas de animar las fiestas con sus bailes) las emplean en sus comparsas durante las fiestas del pueblo, y también cuando acompañan a las autoridades municipales a dejar presentes a otras localidades durante los días de fiesta. Para algunos es significativo como indicador de tradición el mencionar, con cierto dejo de añoranza, el uso de la vestimenta en sus localidades en tiempos no tan remotos; sin embargo, no se promueve ya su uso y en ocasiones sus preferencias en el vestir y calzar se orientan más por la ropa proveniente del mercado nacional e internacional. Incluso entre jóvenes, las marcas de ropa deportiva comercial y de origen extranjero son muy usadas y además deseadas, pero, lo más importante, son de fácil adquisición gracias al constante flujo de bienes y mercancías que la migración trasnacional genera en las localidades.

Los casos se podrían multiplicar si pensamos en cada uno de los individuos con los que he mantenido relación y me han permitido percatarme de las diversas formas y combinatorias que un modelo de reconocimiento y adscripción étnico descentrado posibilita. Deseaba ejemplificar cómo la persistencia étnica y el crecimiento de la adscripción a ésta en la mixteca oaxaqueña ha sido posible por esta actitud de relacionarse con elementos étnicos originarios como la lengua, las creencias, la vida campesina, la vestimenta; pero también con 
elementos nuevos que han aparecido en los últimos años, como son la música de grupos que cantan en mixteco, el Facebook y diversas apps (aplicaciones web), así como páginas de internet que difunden otras maneras de concebirse como mixtecos, en las que algunos sujetos han comenzado a reconocerse, pero otros las dejan pasar, no las conocen, y mucho menos se reconocen a través de éstas.

\section{Conceptualizar la descentralidad y centralidad étnica desde la perspectiva relacional}

Como se dejó ver entre líneas más arriba, una mirada que subvierte la idea de centrado y descentrado y que observa los procesos de reconstitución y reconocimiento étnico desde la práctica cotidiana de manera abierta, conlleva a su vez una orientación teórica diferente de las que han dominado los entendimientos en la teoría de la etnicidad.

Un entendimiento clásico, que como lo han señalado varios autores (Stavenhagen, 1992; Poutignat y Streiff-Fernat, 1995; Brubaker; 2004), estuvo dominado por una tendencia a definir lo étnico a partir de establecer rasgos esenciales, establecidos desde el origen del grupo, que se presentaban de manera similar en cada uno de los sujetos. Éstos, al ser compartidos, permitían la identificación entre individuos, quienes posteriormente formaban colectividades étnicas. De tal modo, dominaría una visión que asumiría el carácter grupal que tienen las colectividades étnicas, donde el grupo social, entendido como lo pensaría Durkheim, funcionaría como un centro gravitatorio donde no sólo las individualidades se diluyen, sino las homogeneidades reinan y conjuran la diferencia.

Por otro lado, como herencia de la caracterización que Max Weber hiciera de los grupos étnicos, no sólo se les veía como una forma organizativa intermedia entre las sociedades formadas por el parentesco (linajes y clanes) y la sociedades nacionales, más apegadas a construcciones convencionales de pertenencia. Se creía también que los vínculos que atan a estos sujetos étnicos son más reales y cuasi-naturales (mismo origen de parentesco, lengua común, fenotipos raciales, mismo espacio territorial, creencias compartidas) y, por lo 
tanto, de su presencia dependía la continuidad y persistencia de un grupo étnico.

Es claro que un hecho que explica el agotamiento del pensar las etnicidades en la comunidad de científicos sociales al entrar el siglo XXI es la consecuencia de las propias incertidumbres que el modelo teórico generó. En primer lugar, buscar las esencias que definían lo étnico y pensar que al ser extendidas a un conjunto de sujetos garantizaban las identidades y persistencias se ha vuelto empíricamente falseable, tal y como lo demostró Rodolfo Stavenhagen (1992) en su texto intitulado La cuestión étnica. Algunos problemas teóricometodológicos".

Mientras que la aparición de procesos de movilidad, migración y éxodo mostró que las persistencias étnicas no están vinculadas del todo a la condición de grupalidad, y mucho menos al supuesto de que todo sujeto comparte la totalidad de los criterios identitarios y fines que sus coetáneos, las diferencias y apuestas distintas por lo étnico comenzaron a ser parte de los panoramas sociales de finales del siglo XX. Por lo tanto, la teoría sobre lo étnico tendrá que lidiar con estos nuevos fenómenos, a pesar de que estos temas podrían resultar riesgosos a los fundamentos con los que se originó una teoría de la etnicidad.

Ahora bien, si asumimos la interesante idea expuesta por Arjun Appadurai (2008), quien lee en la etnografía formas de testimoniar la construcción de lo local y la diferencia, podríamos mirar este intento etnográfico como testimonio de las formas de construcción centrada y descentrada de lo étnico, donde los modelos esencialistas para un caso pueden tener cierta vialidad explicativa y para otro caso ser una limitante. La etnografía sobre la Sierra Tarahumara da cuenta de esa etnicidad, que persiste gracias a la gravitación que ejercen ciertos elementos étnicos como son la lengua, la vestimenta y un estilo de vida que denominamos "de rancherías". Para esta etnicidad, su figuración (término que me apropio de Norbert Elias, 1999) en torno a una entidad social que bien podría ser pensada como un grupo dota de facticidad a esas teorías de la etnicidad que Rogers Brubaker (2006) caracteriza como posturas grupistas (groupism). Éstas, según el autor, representan esa tendencia que mira a las sociedades como compuestas por grupos discretos, diferenciados a través de la construcción de fronteras, donde reina la homogeneidad interna y el interés colectivo (Brubaker, 2006: 8). Incluso la etnografía sobre rarámuris 
migrantes a las ciudades, como la que ha producido Marco Vinicio Morales (2009), refleja esa forma grupal de construir asentamientos en la Ciudad de Chihuahua o en Cuauhtémoc, Chihuahua, además de afirmar que estos grupos se agregan de manera centrífuga en torno a los elementos étnicos de origen serrano.

Por el contrario, la complejidad que existe para abordar y caracterizar aquello llamado etnicidad mixteca desde visiones tradicionales ha sido ya señalada por diversos autores, como Federico Besserer, Michael Kearney, Sylvia Escárcega y Stefano Varese, quienes han mostrado esa condición de originalidad, cambio y contemporaneidad que envuelve tanto a los habitantes de esta región, como a los que han emigrado de ahí. En su mayoría todos estos autores han puesto en relieve que dicha complejidad es el producto de un mundo mixteco cada vez más descentrado, cuya causa principal ha sido la emigración de sus pobladores hacia los Estados Unidos o a las ciudades fronterizas. Desde estas etnografías se ha puesto atención en los cambios culturales que acompañan a esta movilidad, la aparición de formas culturales no originarias y su adopción por parte de sujetos de origen mixteco, pero también se hace énfasis en la permanente reproducción de elementos de origen local, como lo son fiestas, tequios o güezas en escenarios fronterizos, en las metrópolis mexicanas o en poblados y ciudades norteamericanas.

En estas perspectivas resalta que la misma definición de algo llamado mixteco tendría que ser caracterizada como una construcción étnica que trasciende los referentes locales y tradicionales y que se constituye o bien a partir de procesos de translocalidad, o como algo configurado desde la adopción de elementos adquiridos desde múltiples situaciones de vida, como las piensa George E. Marcus (1988). Una forma de construcción étnica que no sólo se da en los escenarios transnacionales o fuera de las localidades, sino que también la observamos al interior de los pueblos emplazados en la Mixteca Alta oaxaqueña.

Resalto que, particularmente, me inscribo dentro de perspectivas que renuncian a seguir conceptualizando la etnicidad, incluida la rarámuri, bajo un enfoque que pondera la existencia de uno o más rasgos substanciales que fundamentan un agregado al cual se le adjudica el ser étnico. Me inclino más a lo que se denominan las vías relacionales que acentúan más las construcciones que se suscitan a partir de las interacciones. Interacciones que se distinguen por 
ser procesuales, dinámicas, concéntricas y descentradas, además de eventuales o perdurables (Brubaker, 2006:11). Afirma Brubaker que el enfoque relacional invita a mirar la etnicidad como una práctica, más que como una sustancia que le asignamos a los sujetos. Una práctica que se despliega en acciones situadas, en una actividad de intercambio simbólico (donde el idioma es importante pero no condición necesaria), en una forma de hacer efectivos esquemas cognitivos, en resolver imperativos organizacionales y políticos, así como en conducir la acción colectiva hacia fines comunes que pueden ser contingentes o durables.

Hay que tener en cuenta que un enfoque que pondera las relaciones puede repensar el papel que juegan los criterios objetivos y subjetivos que se atribuyen a la definición de lo étnico. Bajo esta perspectiva, la lengua, las creencias, los sentimientos de pertenencia y/o las imaginaciones del mundo son elementos que rodean a un sujeto, con los cuales interactúa y construye su horizonte étnico (Appadurai, 2008). Así, desde la vía relacional, en lugar de buscar rasgos o características que definen un grupo, una institución o una práctica social, se opta por mirar las relaciones e interacciones que los sujetos establecen entre ellos, y entre ellos y el mundo de objetos que los circundan, donde sin lugar a dudas se ubican las objetivaciones de lo social que se le presentan al sujeto como ese mundo ya dado. Ya desde comienzos del siglo XX, Simmel expresaba lo anterior de la siguiente manera: "Desde luego que en este caso la sociedad, por así decirlo, no es una substancia, nada concreto en sí mismo, sino un acontecer, la función del recibir y efectuar del destino y de la configuración de uno respecto a otro" (Simmel, 2003: 34).

$\mathrm{Si}$ observamos entonces los rasgos como elementos sociales y culturales con los cuales relacionarse y generar formas de socialización, el modelo aplica tanto para los rarámuri como para los ñu savis. No pienso que la relación sea para los segundos y la esencia para los primeros, lo que veo son dos formas diferentes que posibilitan las relaciones. Una que emerge de la posibilidad del disponer de abanicos amplios y descentrados de elementos culturales con los cuales vincularse, y otra que refleja un abanico más restringido y concentrador de éstos. Y esta cualidad de las relaciones sin duda ha configurado la forma y el contendido de estos dos formatos de sociedad indígena en México y que quizá, si mi modelo es fructífero, lo podríamos extender para hablar de las 
diferencias y semejanzas en los procesos de construcción y reconocimiento étnico en otros pueblos indígenas del país.

La etnicidad la considero aquí, en su dimensión pragmática, como algo que se construye y se va ensamblando a partir de la capacidad de agencia que tienen los sujetos. En ese sentido retomamos las ideas expuestas por Bruno Latour, quien ve en las formas de asociación la construcción de ensamblajes sociales donde "...cada cadena de asociaciones define no sólo distintos vínculos con los mismos elementos; también define diferentes elementos" (Latour, 2014 :369). Para Latour sí existen entidades discernibles, es decir algo a lo que podamos llamar "lo mixteco" o "lo rarámuri", pero éstas se definen por las asociaciones de diversos elementos, pero (y esto es lo más importante) son la existencia y permanencia del vínculo de asociaciones lo que permite que se introduzcan nuevos elementos, que se resignifiquen los antiguos o que se den verdaderos procesos de bricolaje. $\mathrm{O}$ también, puede ser que nuevos elementos que se introducen no tengan asidero y significación y que o no se retomen, o bien se conviertan en elementos diluyentes de las configuraciones previas y aparezcan otras formas sociales que bien pueden significar la renuncia a un modo de vida anterior.

No obstante el modelo relacional en su versión simmeliana que es asumido aquí, las consecuencias diluyentes de lo social, en su postura, son repensadas para explicar la vigencia de las instituciones que encarnan la sociedad rarámuri, como son el korima, las rancherías, las fiestas de patio y templo; y aquellas que constituyen la mixteca, con sus fiestas patronales, sus güezas, tequios y sus sistemas normativos.

A pesar de las simpatías que me causa la postura anterior, considero que ésta se puede apoyar en las tesis de una vertiente relacional que es menos diluyente respecto de las formas sociales que se producen en la asociación; me refiero a la posición que se caracteriza como constructivista y relacional. Como lo muestra Philippe Corcuff, bajo esta perspectiva no se niega la existencia de las formas colectivas o de las configuraciones sociohistóricas, más bien se ve a las relaciones sociales como una entidad metodológicamente más fructífera para develar los fenómenos sociales que se ocultan dentro de las perspectivas que podríamos llamar sustancialistas. Las formas colectivas serían, según Corcuff, 
entidades secundarias o cristalizaciones de las relaciones sociales tomadas en un momento de su desenvolvimiento histórico (Corcuff, 2013 :27).

Para Corcuff se trata ahora de analizar cómo se construyen mundos objetivados que surgen de las acciones e interacciones de los sujetos y de éstos con el entorno, pero que a su vez también moldean al individuo y a los grupos sociales; de ahí la gran cercanía que tiene el enfoque relacional con visiones constructivistas o con aquellas que reivindican la praxis de los agentes sociales.

Es a nivel de los procesos de construcción étnica a través de las relaciones que podemos analizar las persistencias de los reconocimientos étnicos y el que en la actualidad algunos grupos indígenas sigan existiendo ante las amenazas de procesos globales y tendientes a la universalización. Pero también, seguir las relaciones nos permite, como parte de otro momento del análisis social, aquel que combina tiempo y espacio, adentrarnos a la morfogénesis de la sociedad, entendida como lo hace Margaret Archer (2014). A partir de esta dimensión analítica se podrá conocer la adopción de nuevas prácticas e instituciones que comienzan a ser parte de los elementos que un sujeto étnico dispone para construir su pertenencia y reconocerse como mixteco o rarámuri.

\section{Consideraciones finales: persistencias y riesgos en un mundo contemporáneo}

Después de las prognosis que realizaran los analistas del sistema mundo y las globalizaciones (McLuhan y Powers, 2015; Wallerstein, 2005; Castells, 2006), quienes vaticinaban la inminente homogenización de las formas sociales $y$ culturales ante la conectividad entre los países del mundo, y por lo tanto el anuncio del fin, o de la dificultad que implicaría en esta era vivir desde las experiencias de vida diversas y locales, la historia contemporánea mostró que las persistencias y el ser indígena es algo que tiene vigencia y futuro en el siglo XXI (Clifford, 2013; Appadurai, 2008; Benhabib, 2006).

Pero, como bien lo ha mostrado Gustavo Lins Ribeiro (2018), la constatación de las persistencias, resistencias y reactualización de las formas de vida indígena no debe ocultar el actuar de fuerzas como el mercado, los medios de comunicación masiva, el control tecnológico, los ejes productores de poder y la diseminación de discursos como desarrollo y crecimiento, entre otros. Se trata de fuerzas homogeneizadoras actuantes que atentan contra la diversidad. 
Incluso, como lo señala Gustavo Lins, pareciera que estas se transfieren a escala global desde poderes oblicuos y modelos no problematizados que se naturalizan de tal forma, que hacen pensar que las resistencias a éstas son absurdas y, agregaría, que hacen palpable que las diferentes apuestas tiendan a dificultar su reproducción (Lins, 2018: 221).

En nuestros días, los antropólogos que estudian las emergencias y persistencias étnicas en el mundo global han llegado a un consenso teórico en el que se afirma que estas vigencias se explican por la particular forma en que los sujetos étnicos logran relacionarse y posicionarse frente a los procesos generalizadores y universalistas. John y Jean Comaroff (2009) sustentaban que las formas en que los grupos étnicos se están vinculando con esas fuerzas globales son el turismo, la mercantilización de todo objeto vendible, incluyendo las tradiciones, las artesanías, la implementación de recursos tecnológicos usando códigos culturales y sociales diversos con el objetivo de expandir mercados. Todos estos elementos, señalan los Comaroff, definirán el escenario del concierto de las etnicidades del futuro. Ellos denominan a esta situación etno-futuros, y los ven como los escenarios donde las etnicidades persistirán debido a las propias apuestas que los colectivos o los sujetos étnicos tendrán por utilizar estas fuerzas, adaptarse a ellas o renegociar otras formas de lo étnico, ajustándose a las demandas del mercado, el turismo, las ONG, las pretensiones de industrias por despojar territorios y recursos, y los servidores públicos encargados de canalizar recursos para apoyar a las culturas locales.

Y como bien lo señalan los Comaroff, estos etno-futuros, definidos a grandes rasgos como la interacción de sujetos étnicos en escenarios, políticas y situaciones en un mundo global y gobernado por las reglas del capitalismo neoliberal, han permitido la emergencia de objetivaciones de los elementos culturales que articulan las etnicidades. Por ejemplo, ahora la consciencia de los territorios y sus riquezas es algo que emerge de las luchas contra las empresas extractivas, pero también la valoración de ciertas costumbres, fiestas, utensilios, vestimentas "típicas", creencias y formas de vida es algo que se ha posibilitado por las puestas en la escena global de las etnicidades.

Sin embargo, estas articulaciones indígenas, como las denomina Clifford (2013), no sólo están marcadas por la novedad y emergencia que conlleva el mundo contemporáneo. Las apuestas que explican las persistencias también implican articulaciones desde el mundo tradicional histórico. Para Clifford no 
se trata de ver sobrevivencias o reproducciones de lo viejo en lo nuevo, sino de una actualidad de los pueblos indígenas. Una modernidad, afirma, de la experiencia indígena que se explica por esas formas de relacionar el regreso (entendido como lo tradicional heredado) con las visitas a lo nuevo (las tecnologías, las nuevas formas de lucha política, la creación de museos locales, etc.); por no disociar la apuesta y el deseo por un futuro con la nostalgia y, como bien lo expresan los mixtecos, relacionarse simultáneamente con lo distante y ajeno y con lo cercano y local.

Agrega Clifford que las conexiones son motivadas por las contingencias y escenarios que ponen en riesgo las existencias étnicas o que implican asumir los nuevos retos que el mundo global les lanza. Pero no siempre el escenario del mundo indígena está marcado por el fluir de las articulaciones y la emergencia de lo nuevo. En momentos históricos las expresiones perduran, el discurrir de las relaciones dan paso a aquello que Durkheim llamó el nivel morfológico de la sociedad, donde se nos permite entrever las formas culturales que definen un colectivo étnico y se estabilizan los elementos culturales por medio de los cuales los sujetos se reconocen étnicamente, materializando aquello que Appadurai llamó construcciones de lo local (2008).

Siguiendo a Appadurai, es justo a partir de estas experiencias de vida de los sujetos en mundos locales que se configuran horizontes étnicos (ethnoscapes) desde los cuales los sujetos interpretan las experiencias en un mundo globalizado, les dan sentido a las prácticas, discursos simbólicos, narrativas y objetos que los flujos mercantiles y los éxodos de personas ponen en contacto. Pero también, desde estos horizontes étnicos emergen las apuestas por cómo vivir en este escenario global, determinando en qué flujo de corriente global se pueden colocar y persistir con todo y sus formas culturales de construcción de lo local.

Lo anterior no excluye que sobre otros flujos se monten los sujetos étnicos o que existan fuerzas que los aten a una corriente contraria, por lo que las persistencias se ven amenazadas tanto por la imposición de otros estilos de vida, como por la desarticulación de sus referentes étnicos. Pero, como bien lo indican Appadurai, Clifford y Lins Ribeiro, determinar donde sucederá 
lo anterior o dónde dominara la construcción de lo local es algo que sólo la experiencia empírica puede indicar a posteriori.

No afirmo que la etnicidad rarámuri está en riesgo, pero sí considero que sus articulaciones a este mundo global le han significado un reto mayor que explica sus múltiples formas de resistencia, hecho que ha sido registrado en la etnografía actual. En ésta se deja constancia de sus luchas por los recursos, sus territorios y la reivindicación de los derechos humanos y culturales de los pueblos rarámuri. Sin embargo, su adaptación a los flujos de las fuerzas globales, a esas que los Comaroff ven como los nuevos horizontes de las etnicidades, es algo que, a diferencia de los mixtecos, no han incorporado entre sus referentes para la construcción de los reconocimientos étnicos. El turismo global sigue siendo capitalizado en la Sierra Tarahumara por los mestizos y los rarámuris sólo son el "indio" que vende sus artesanías y a quien se le extrae su imagen para emplearse en folletos turísticos, nombrar hoteles, restaurantes y de vez en cuando volver a la cultura rarámuri un atractivo que ofertan los mestizos como tour.

Contrasta con la manera en que hoy se hacen visibles los mixtecos en el escenario global y local. Es común encontrar en las calles de la Ciudad de México, así como en las de Oaxaca, en Tijuana y en Ciudad Nezahualcóyotl, tiendas de abarrotes, restaurantes, comercios que se llaman "El Mixteco", cuyos dueños se identifican con esa etnicidad. En épocas recientes el cine mexicano, a partir de la última película de Alfonso Cuarón, titulada Roma, puso en el centro de la consciencia nacional la figura de una mujer originaria de la región mixteca que en la película habla la lengua tun savi. En redes sociales y en radio, así como en otros medios de comunicación, las personas originarias de la región que se reconocen como mixtecos, enarbolaron la figura de la actriz como representante del orgullo local y cultural.

En una investigación en curso sobre la representación del ser mixteco en la red social Facebook, he encontrado cerca de cincuenta páginas o muros de usuarios de la red, que utilizan el sobrenombre de mixteco, ñu savi, tun savi o mixteca. En estos muros se exponen contenidos sobre la región, sobre prácticas culturales, se motiva al uso de la lengua y se reivindican muchos de los referentes tradicionales de la etnicidad mixteca. Pero es importante señalar que, si observamos cada muro como el ejercicio de un actor individual por reconocerse mixteco, encontramos ese ejercicio relacional de usar algunos 
referentes culturales y discriminar otros, los cuales otro gestor de una página Facebook podrá reivindicar como criterio de su identidad. Por ejemplo, para algunos internautas el uso de la lengua es importante, incluso se publican mensajes e imágenes en mixteco, pero para otros no es relevante la lengua para evidenciar que son mixtecos y que se reconocen originarios de la región, o que comparten los estilos de vida, entre otras cosas.

Constantemente, en redes y otros medios, nos enteramos que ingenieros en sistemas de origen mixteco desarrollan aplicaciones digitales para la enseñanza de la lengua o para su transmisión a las nuevas generaciones. Son iniciativas de jóvenes, pero que también comparten adultos, el que las fiestas $\mathrm{y}$ aspectos como leyendas y tradiciones sean difundidas por plataformas como blogs o YouTube. En estos sitios del mundo digital podemos encontrar incluso leyendas animadas contadas en su lengua y dobladas al castellano, un ejercicio que realizan estos nuevos actores mixtecos que aprovechan las nuevas tecnologías de la comunicación.

Es sabido que la migración de mujeres y hombres mixtecos a los EE.UU, por ejemplo, ha permitido no sólo la introducción de remesas que se utilizan para el financiamiento de fiestas y recursos, sino también de las nuevas redes que posibilitan los sistemas de entregas de paquetería exprés, como son FedEx, DHL, UPS, y hacen posible que alimentos, artesanías y recursos circulen de la región a localidades en los Estados Unidos, con lo cual los procesos de reconocimiento étnico se dan más allá de las fronteras nacionales y locales.

Para concluir podría afirmar que la posibilidad de establecer relaciones descentradas y múltiples en un contexto de globalización resulta ser ventajoso para poblaciones cuyos horizontes étnicos aún tienen una tarea central en la conducción de sus vidas como sujetos cultural y socialmente diferentes. Los mixtecos son un claro ejemplo de esta situación, y podríamos afirmar que se trata de un pueblo indígena que se distingue por su contemporaneidad y su apertura a tener un futuro étnico exitoso o, al menos, no en riesgo. Lo anterior no excluye que ellos padezcan las consecuencias perversas de los procesos de globalización. Ésta no solo se les presenta como el escenario desde el que se introducen nuevos sentidos, se ofertan nuevos referentes para la construcción de pertenencias o se les dispone de otros medios para representarse étnicamente. Ellos también atestiguan la desarticulación de comunidades, ya sea a partir de los procesos de extracción de recursos y despojo de tierras o del padecer el 
abandono de pueblos y lugares de la región a causa de la pobreza, las hambrunas y las crisis ecológicas que motivan los éxodos mixtecos por todos conocidos. Además, padecen los persistentes estigmas contra la lengua, la vestimenta y otros elementos de su etnicidad que han llevado a que muchos individuos opten por abandonar su uso por temor a la discriminación. Sin embargo, ahí están y su presencia en el imaginario nacional como una población que mantiene una cultura y tradición es hoy muy extendida, así lo entienden ellos y su apuesta es mantener o acrecentar esa presencia.

\section{Bibliografía}

Appadurai, Arjun (2008) Modernity at Large. United States of America: The University of Minnesota Press.

Archer, Margaret (2014) Teoría social realista. El enfoque morfogenético. Chile: Universidad Alberto Hurtado.

Benhabib, Seyla (2006) Las reivindicaiones de la cultura. Igualdad y diversidad en la era global. Argentina: Katz.

Berger, Peter y Thomas Luckmann (1997) Modernidad, pluralismo y crisis de sentido. La orientación del hombre moderno. España: Paidós.

Brubaker, Rogers (2006) Ethnicity without groups. United States of America: Harvard University Press.

Castells, Manuel (2006) La era de la información: Economía, sociedad y cultura. La sociedad red. México: Siglo XXI.

Clifford, James (2013) Returns. Becoming indigenous in the Twenty-First Century. United States of America: Harvard University Press.

Clifford, James (1999) Itinerarios transculturales. Barcelona: Gedisa.

Comaroff, John y Comaroff, Jean (2009) Ethnicity, Inc. United States of America: The University of Chicago Press.

Corcuff, Philippe (2013) Las nuevas sociologías. Principales corrientes y debates, 1980-2010. Buenos Aires: Siglo XXI. 
Elias, Norbert (1999) Sociología fundamental. Barcelona: Gedisa.

Figueroa, Alejandro (1985) "Los que hablan fuerte. Desarrollo de la Sociedad Yaqui” en Noroeste de México. Centro Regional del Noroeste. México: Instituto Nacional de Antropología e Historia-Secretaría de Educación Pública.

González, Luis (1984) Crónicas de la Sierra Tarahumara. México: Secretaría de Educación Pública.

Gotés, Luis (2012) “La Sierra Tarahumara, sus culturas étnicas y la apropiación del medio ambiente" en Luis Eduardo Gotés Martínez (et.al.). Los Pueblos Indigenas de Chihuahua. Atlas Etnográfico. México: Instituto Nacional de Antropología e Historia. pp. 37-73.

Kirchhoff, Paul (1960) Mesoamérica. México: Sociedad de alumnos de la ENAH.

Kirchhoff, Paul (2008) "Recolectores y agricultores en el Gran Suroeste: un problema de clasificación”, Antropología. Revista interdisciplinaria del Instituto Nacional de Antropología e Historia, 0(82), pp. 72-89.

Latour, Bruno (2014) Reensamblar lo social. Una introducción a la teoría del actor-red. Buenos Aires: Manantial.

Lins, Gustavo (2018) Otras Globalizaciones. México: Universidad Autónoma Metropolitana, Unidad Iztapalapa y Unidad Lerma-Gedisa.

Lumholtz, Carl (1986) El México desconocido. T.I. México: Instituto Nacional Indigenista.

Marcus, George (1998) "Ethnography in/of the World System: The Emergence of Multi-Sited Ethnography (1995)", Ethnography through Thick \& Thin, United States of America: Princeton University Press. pp. 79104.

McLuhan, Marshall y Powers, B. R. (2015) La aldea global. Transformaciones en la vida y los medios de comunicación mundiales en el siglo XXI. La globalización del entorno. Último trabajo de Marshall McLuhan. España: Gedisa.

Morales, Marco Vinicio (2009) Organización sociopolítica rarámuri en la Ciudad de Chihuahua. Intermediarios y actores de la intervención en el asentamiento "El oasis", Tesis para optar por el grado de maestría en Antropología Social, Chihuahua: Escuela de Antropología e Historia 
del Norte de México-Centro de Investigaciones y Estudios Superiores en Antropología Social.

Poutignat, Philippe y Streiff-Fenart, Jocelyne (1995) Théories de l'ethnicité. Suivi de Les groupes ethniques et leurs frontiérs par Fredrik Barth. France: Presses Universitaires de France.

Sariego, Juan Luis (2002) El indigenismo en la Tarahumara: identidad, comunidad, relaciones interétnicas y desarrollo en la Sierra de Chihuahua. México: Instituto Naciona Indigenista-Instituto Nacional de Antropología e Historia.

Simmel, Georg (2003) Cuestiones fundamentales de sociología. Barcelona: Gedisa.

Spicer, Edward (1997) Cycles of Conquest. The impact of Spain, Mexico and the United States on the Indians of the Southwest, 1533-1960. United States of America: University of Arizona Press.

Stavenhagen, Rodolfo (1992) "La cuestión étnica. Algunos problemas teóricometodológicos”, Estudios Sociológicos, El Colegio de México, 10 (28), pp. 51-76.

Wallerstein, Immanuel (2005) Análisis de sistemas-mundo: Una introducción. México: Siglo XXI. 